\title{
Aplicação da metodologia CommonKADS na implementação de projetos de e-gov na perspectiva de uma empresa de software
}

\author{
PabloPocopioMertins Esp; Mestrando do Programa de Engenharia e Gestão do Conhecimento (PPEGC/UFSC). Universidade do \\ Estado de Santa Catarina (UDESC) - Brasil. pablopmartins@gmail.com \\ DenilsanSell Dr; Universidade Federal de Santa Catarina (UFSC) - Brasil. denilsonsell@gmail.com \\ MauíáojoæéFibeiroRotta Msc; Doutorando do Programa de Engenharia e Gestão do Conhecimento (PPEGC/UFSC). Universidade \\ Federal de Santa Catarina (UFSC) - Brasil. maurotta@gmail.com \\ AntônioRefad Otega Esp; Universidade Federal de Santa Catarina (UFSC) - Brasil. antonioiae@gmail.com
}

\section{RESUMO}

As iniciativas de implantação de projetos de governo eletrônico são um fenômeno global e nas últimas décadas é relatado um alto índice de fracasso. 0 ambiente governamental, contexto desses projetos, é complexo, repleto de ações desarticuladas, regras rígidas e tem o envolvimento de muitos atores, com interesses diversos; dentre eles, as empresas de software. Diante desta perspectiva, o objetivo deste trabalho é aplicar a metodologia CommonKADS para apoiar a gestão de projetos de governo eletrônico e a memória organizacional resultante. Para esse fim utilizou-se a visão qualitativa de pesquisa baseada em entrevistas semiestruturadas com dez representantes deste ramo em Florianópolis e, em seguida, aplicou-se o CommonKADS; como resultado, foi sugerido um sistema baseado em conhecimento (SBC) para integrar os artefatos de memória organizacional produzidos pela empresa.

Palavras chave: Governo eletrônico. Fatores críticos de sucesso. CommonKADS. Gestão de projetos.

\section{Applying the CommonKADS methodology in the implementation of e-gov projects in the perspective of a software company}

\begin{abstract}
The initiatives of e-government projects are a global phenomenon and in the last decades, research reports a high rate of failure. The governmental environment, context of these projects, is complex, full of disarticulated actions, rigid rules and has the involvement of many actors, with diverse interests, amongst them, software companies. From this perspective, the objective of this work is to apply the CommonKADS methodology to support the management of e-government projects and the resulting organizational memory.To achieve this purpose, the research team employed a qualitative research approach and ten semi-structured interviews with representatives of software companies in Florianópolis were applied, followed by the application of the CommonKADS. Asa result, a knowledge-based system was suggested to integrate the artifacts of organizational memory produced by the company.
\end{abstract}

Keywords: e-Government; Critical success factors; CommonKADS; Project management 


\section{INTRODUÇÃO}

Os projetos de governo eletrônico (e-gov) se tornaram um fenômeno mundial que se iniciou com a inserção dos computadores na administração pública, passando a disponibilizar serviços até a nova fase que permite a participação do cidadão no processo decisório (PACHECO et al, 2015). Verificou-se na literatura que esses projetos têm altas taxas de resultados inócuos ou acabam sendo considerados falhos; essas taxas tornamse ainda mais altas em países subdesenvolvidos ou em desenvolvimento (RANA; DWIVEDI; WILLIAMS, 2013).

Segundo Pacheco et al (2015), um projeto de egov exitoso apresenta características comuns tais como liderança, integração, visão de longo prazo, e comprometimento com a melhoria dos serviços e processos ao longo dos anos.

O contexto de desenvolvimento desses projetos é multidisciplinar e complexo, (PURÓN-CID, 2013), pois tem como participantes diversos entes públicos e privados, e outras organizações, muitas vezes com interesses distintos.

Tendo em vista a complexidade destes projetos, é necessário que sejam conduzidos por metodologias de gestão que os tornem mais eficazes. Sarantis et al (2010) defendem que sem o método de gestão de projetos apropriado, aqueles que trabalham em um projeto de egov podem não ter ferramentas necessárias para planejar e organizar tarefas, responsabilidades e marcos.

Em paralelo à engenharia do conhecimento, oriunda da inteligência artificial e da engenharia de software, oferece meios para adquirir os conhecimentos dispersos na organização e utilizá-los da forma mais efetiva: automatizando processos, capturando o conhecimento para reutilização e retendo o conhecimento dos especialistas (PACHECO et al, 2015). Para isto, a metodologia CommonKads (SCHREIBER et al, 2002) se apresenta como adequada para esta finalidade, pois trata-se de uma metodologia que se preocupa não só com aquisição e modelagem do conhecimento, mas com todo o ciclo de vida do projeto (ABEL; FIORINI, 2013).

Assim, a pergunta norteadora deste trabalho é: quais contribuições a metodologia CommonKads pode oferecer para a gestão de projetos de egov de uma empresa de desenvolvimento de software?

E desta pergunta retira-se o objetivo geral deste trabalho: aplicar a metodologia CommonKADS, da mesma forma que os trabalhos de Lopes et al (2011) e Sewald Junior et al (2012), sugerindo soluções práticas ao processo de gerenciamento de projetos de egovao ente privado envolvido neste processo.

\section{DESENVOLVIMENTO}

Nesta parte do artigo são apresentados os pontos teóricos que são mais relevantes para o desenvolvimento da pesquisa.

\subsection{Governo Eletrônico}

A maioria das definições so bre governo eletrônico (e-gov) giram em torno da necessidade de os governos proporcionarem serviços de qualidade, resultados políticos e maior envolvimento dos cidadãos por meio das TICS (Tecnologias da Informação e Comunicação) conforme conceito da OCDE (2004) citado por Park e Kim (2014).

Com o passar dos anos, os cidadãos passaram a exigir seus direitos e serviços através de informações obtidas na rede, e requereram um governo mais transparente, com dados abertos e até mesmo seus protestos são feitos ou começam de forma on-line. Todos estes são aspectos da governança, que passa acontecer no meio da intemet, e assim, apresenta um aspecto de rede (Guha e Chakrabarti, 2014). Segundo Kumar e Best (2006) além da transparência, a participação é um elemento essencial do projeto de egov.

0 mundo contemporâneo e, principalmente, as TICs tornam o egov complexo e multidisciplinar. Os governos vêm se reinventando, transformando-se com elementos do mundo pós-revolução industrial, como a gestão do conhecimento (CHANG et al, 2009).

Desta forma, os projetos de egov podem contribuir para a produtividade da administração pública, com a melhora nos processos de tomada de decisão (BIGDELI; KAMAL; CESARE, 2013). Esse diferencial competitivo é ratificado pelos estudos de Franke et al (2015) e Panda e Sahu (2014); que os projetos de egov são soluções importantes para diminuir custos e o retrabalho, alcançar uma estrutura mais enxuta e reduzir níveis de corrupção 
em função dos cortes de intermediários na prestação dos serviços públicos, e assim, gerar competitividade perante os demais países.

No entanto, a implementação desses projetos, em geral, sofre com atrasos e falhas em suas entregas. E, a bem-sucedida execução depende da interação de uma série de elementos: pessoas, tecnologia, organização, recursos financeiros e políticos, além da correta gestão de riscos relacionada a complexidade e inovação inerente a projetos de egov (AICHHOLZER, 2004).

Em tratando-se de projetos governamentais, existem riscos e fatores críticos que caso não sejam trabalhados levam o projeto ao fracasso, dentre eles o primeiro aspecto que surge é o político. Segundo Chowdhury et al (2006 apud SARANTIS et al, 2010, p. 308) "a política tende a dominar os projetos do setor público, onde os agentes de mudança envolvidos são geralmente motivados por interesse próprio e/ou a situação política favorece a iniciativa". Ou seja, há projetos de governo em detrimento a projetos de Estado.

Por conta do cenário descrito é necessário um método personalizado ao setor público, já que as nuances deste contexto são muito diferenciadas. Afirmam Sarantis et al (2010, p. 302): "Sem o método de gerenciamento de projetos apro priado, aqueles que gerenciam um projeto de e-gov (...) não têm as ferramentas necessárias para planejar, organizar, monitorar e reagendar tarefas, responsabilidades e marcos.". Desta forma é recomendável que seja desenhada uma metodologia de gestão de projetos capaz de suprir as particularidades da administração pública.

\subsection{Engenharia do Conhecimento - Commonkads}

Engenharia e Gestão do conhecimento são áreas recentes na administração de negócios, que buscam meios de adquirir conhecimento e utilizá-lo como recurso-chave nas organizações modernas. Administrar esse conhecimento torna-se difícil sem utilizar o potencial dos sistemas de informação e conhecimento (SCHREIBER et al, 2002).

O desenvolvimento de aplicações baseadas em conhecimento é uma tarefa complexa que apresenta dificuldades. Isto deve-se ao fato de que projetos baseados em conhecimento não podem ser abordados com metodologias comuns de engenharia de software, pois os ciclos de vida dessas aplicações são diferentes em muitos aspectos (SUREEPHONG et al, 2007).

Ao tratar-se de conhecimento, diversas são as situações em que o mesmo faz parte de um ambiente exclusivo do fabricante do produto ou do especialista da área a qual pretende-se atuar. Esta realidade é comum, e a engenharia do conhecimento se propõe a ajudar em (VAN DER VELDEN et al, 2012): 1) automatizar processos do ciclo de vida de desenvolvimento de produto, para reduzir tempo e custo; 2) garantir a qualidade dos resultados dos processos; 3) capturar conhecimento para posterior reutilização; 4) reter o conhecimento de especialistas; 5) criar uma estrutura para os processos de desenvolvimento.

As metodologias têm expandido seu âmbito de aplicação. Desenvolvedores de sistemas e engenheiros de conhecimento perceberam que o trabalho técnico bem-sucedido só é possível se for situado dentro do contexto organizacional mais amplo: no desenvolvimento de sistemas baseados no conhecimento, e também na gestão do conhecimento, engenharia de requisitos, modelagem empresarial e reengenharia de processos de negócio (SCHREIBER et al, 2002).

CommonKADS é uma metodologia de engenharia do conhecimento, com origem no programa europeu Esprit, que é utilizada em todo o mundo por entes públicos e privados, e é referência no desenvolvimento de sistemas baseados em conhecimento, com maior uso no continente o qual foi desenvolvida (WERNECK, 2006; ABEL; FIORINI ,2013). A metodologia baseia-se no ciclo de vida clássico (em cascata) - quanto à divisão de fases e no ciclo de vida espiral - quanto ao gerenciamento do projeto, composto de quatro atividades: revisão, avaliação de riscos, fazer plano detalhado para a próxima fase e monitoramento (DIAS; PACHECO, 2009).

Seus principais artefatos são modelos previamente definidos, e o principal destes, é o modelo do conhecimento, empregado para modelar o conhecimento para a resolução de problemas, realizado por um agente (humano ou computacional) responsável pela tarefa (WERNECK, 2006). Os modelos são definidos em 3 níveis: nível do contexto (organização, agente e tarefa), conceito (conhecimento e comunicação) e do artefato (projeto), conforme pode ser observado na Figura 2. 
Figura 2 - Modelos do CommonKADS

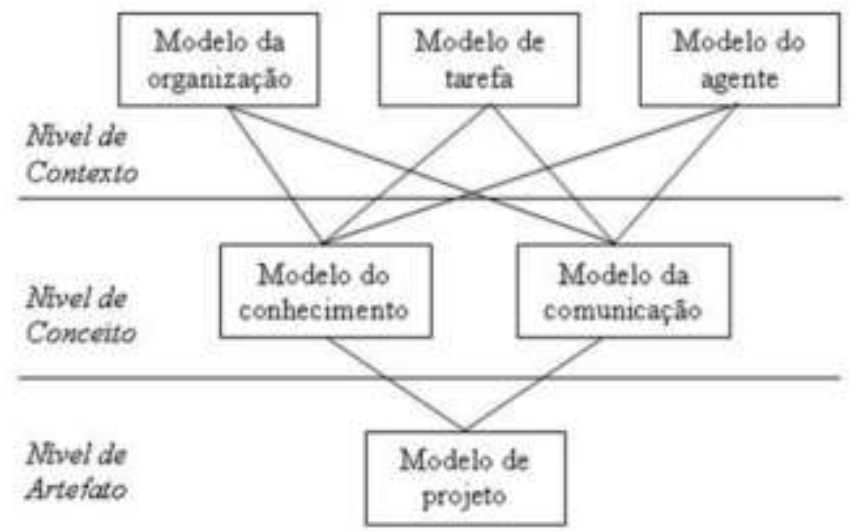

Fonte: Dias e Pacheco (2009, p. 4) traduzida de Schreiber et al (2000, p. 18).

Conforme Schreiber et al (2002), o modelo de organização constrói a análise das principais características da organização, visando identificar problemas e oportunidades para os sistemas de conhecimento atuarem, além de estabelecer a viabilidade e avaliar impactos. 0 modelo de tarefas analisa o layout da tarefa global, suas entradas e saídas, condições e critérios de desempenho, além dos recursos e competências necessárias. No modelo do agente são apresentados os executores das tarefas, suas características, competências, direitos e restrições. Além disso, demonstra as ligações de comunicação entre agentes na execução de alguma tarefa.

O modelo de conhecimento explica os tipos e estruturas de conhecimento utilizado na execução de uma tarefa, e descreve o papel que diferentes componentes do conhecimento desempenham na solução de um problema. 0 modelo de comunicação define as transações comunicativas entre os agentes, por haver possibilidade de interação entre estes.

Por fim, o modelo de projeto fornece a especificação técnica em arquitetura, plataforma de implementação, módulos de software, construções representacionais e mecanismos computacionais. No entanto, nem todos os modelos precisam ser construídos, dependendo das metas do projeto ou das experiências adquiridas na execução (SCHREIBER et al, 2002).

\section{METODOLOGIA}

Esse trabalho é pautado nas ideias da pesquisa social aplicada, dessa forma pretende-se investigar não somente conceitos teóricos e leis a respeito da temática definida, mas a aplicação da metodologia CommonKADS à implementação de projetos de egov.

Assim, para atingir o objetivo traçado tem-se como estratégia de pesquisa, qualitativa, o estudo de caso conforme Yin (2015). Sustenta Gil (2008) que o estudo de caso tem o caráter de aplicar a teoria numa realidade que envolva o problema.

Desta forma, busca-se confrontar a teoria com a realidade de uma empresa de software no contexto de projetos de egov, então, para obtenção dos dados foram utilizadas entrevistas semiestruturadas, gravadas, conforme orienta Taylor e Bogdan (1984), com os responsáveis pela implementação destes projetos. Também se coletou observações e reflexões sobre as reações dos entrevistados assim como aspectos inerentes aos locais (Merriam, 1998).

As entrevistas foram efetuadas com dez colaboradores ligados a esse processo, dentre estes: gerentes de projeto, gerente de portfólio e líderes de implantação de projetos e duraram em média de quarenta minutos. A escolha destes foi feita pelo método não probabilístico e de forma intencional com o auxílio do gatekeeper. 0 período de coleta dos dados deu-se de setembro de 2016 até novembro do mesmo ano.

Para análise dos dados, o conteúdo foi rotulado e classificado por meio de seus aspectos mais importantes. Com esses achados em mãos aplicou-se a metodologia CommonKADS a fim de propor uma nova sugestão sobre como o ator, empresa de software, pode melhorar a implementação dos projetos de egov. Em suma, essa pesquisa pode ser classificada como: científica, exploratória e descritiva (Gil, 2008). 
Como limitante desta pesquisa é relevante salientar que por se tratar de um estudo de caso, não se permite generalizações e outro limitante é o tempo e espaço restritos ao momento de realização deste estudo (Yin, 2015), ou seja, os dados que foram coletados e analisados neste estudo são dados transversais.

\section{APLICAÇÃO DA METODOLOGIA COMMONKADS}

O CommonKADS proporciona uma visão conceitual do conhecimento da organização, tornando explícito o conhecimento tácito das pessoas por meio da aquisição, descoberta ou representação de conhecimento. A seguir demonstrar-se-á a aplicação da metodologia.

\subsection{Modelo da Organização}

Neste modelo (quadro OM-1) é caracterizada a organização estudada, e assim, são analisados os problemas, as oportunidades a ela inerentes.

Quadro 1 - OM-1 aplicada ao estudo.

\begin{tabular}{|c|c|}
\hline \multicolumn{2}{|r|}{ Modelo de Organização - OM - 1} \\
\hline 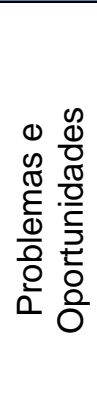 & $\begin{array}{l}\text { - Aumento da quantidade de projetos em função dos novos mercados a serem atingidos } \\
\text { (Ministérios Públicos, Procuradorias de Estado e Município, Escritórios de Advocacia e } \\
\text { Tribunais); } \\
\text { - } \quad \text { Dificuldades na captação de recursos humanos internos para execução de novos } \\
\text { projetos; } \\
\text { - Falta de espaço para trocas sistemáticas entre os gerentes de projetos das memórias } \\
\text { organizacionais de cada projeto; } \\
\text { - Constante troca dos apoiadores externos do projeto (descontinuidade política); } \\
\text { - Múltiplos interesses dos demais stakeholders envolvidos; } \\
\text { - Alta rotatividade de colaboradores diretamente ligados à implantação do projeto. }\end{array}$ \\
\hline 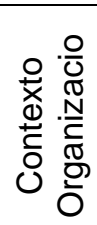 & $\begin{array}{l}\text { Negócio: "Soluções de tecnologia especializadas para processos de negócio". Missão: } \\
\text { "Fazer a diferença na vida das organizações e das pessoas, provendo soluções de } \\
\text { tecnologia especializadas em processos de negócio". Visão: "Ser líder de mercado em todos } \\
\text { os segmentos que atuar, realizando o resultado } 20 / 20 \text { ". Valores: "Sustentabilidade, } \\
\text { Inovação, Confiança, Valorização de Pessoas e Relações Duradouras". }\end{array}$ \\
\hline 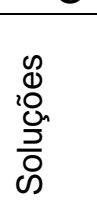 & $\begin{array}{l}\text { 1) Proposição de um sistema que prospecte as competências, habilidades dos } \mathrm{RH} \\
\text { (Páginas Amarelas); } 2 \text { ). Organizar um espaço na rede interna para propiciar as trocas entre } \\
\text { os gerentes de projetos e demais envolvidos; 3) Mapeamento sistemático dos stakeholders } \\
\text { envolvidos; 4) Proposição de sistema que mantenha memória dos projetos, funcionando como } \\
\text { fonte de consulta. }\end{array}$ \\
\hline
\end{tabular}

Fonte: Autores (2017)

Ainda no modelo da organização é importante explanar sobre a disposição do organograma da organização pesquisada, a qual emprega um organog rama híbrido com estrutura superior funcional (staff) e outra com o superior divisional que gerencia as unidades de negócios. Também permeia essa estrutura os projetos (internos e externos), onde são alocados colaboradores das diferentes áreas da organização. 
Figura 1 - Representação do organograma da organização estudada

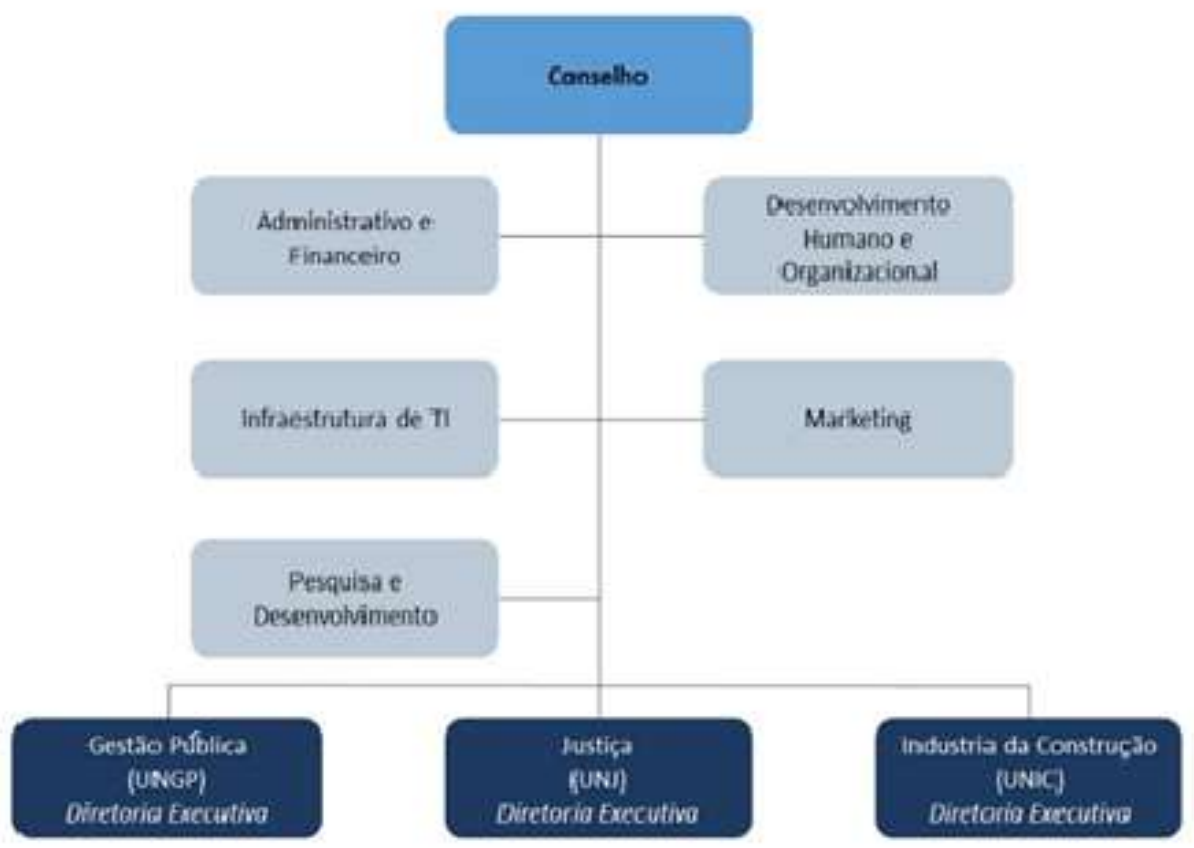

Fonte: Autores (2017).

Em sequência, ainda dentro do modelo da organização, confeccionou-se a OM-2. Esta tem o intuito de verificar a estrutura, processos, pessoas, recursos, conhecimentos e fluxos de cultura e poder que podem influenciar as decisões tomadas, construindo um arcabouço empírico desta organização para futura decisão sobre a solução de conhecimento a ser ou não implantada.

Quadro 2- OM-2 aplicada ao estudo.

\section{Planilha de Aspectos Variantes OM - 2: Modelo de Organização}

\begin{tabular}{|c|c|}
\hline \multicolumn{2}{|r|}{ Planilha de Aspectos Variantes OM - 2: Modelo de Organização } \\
\hline 冚 & $\begin{array}{l}\text { Organograma da empresa (Figura 1): Utiliza-se da estrutura por projetos (matricial) } \\
\text { concomitante a estrutura por segmentos de mercado. Modelo de organograma híbrido: } \\
\text { Composta por: Conselho deliberativo; Administrativo Financeiro; Infraestrutura de Tl; Pesquisa e } \\
\text { Desenvolvimento; Desenvolvimento Humano e Organizacional; Marketing. Na estrutura } \\
\text { divisional encontram-se: 1) Unidades de Gestão Pública; 2) Unidades de Justiça; 3) Unidades de } \\
\text { Indústria da Construção. }\end{array}$ \\
\hline 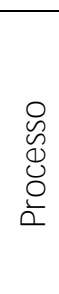 & $\begin{array}{l}\text { 1) Solicitação de um novo projeto; 2) Revisão, avaliação de prioridade, porte e dificuldade (Gestor } \\
\text { de portfólio);3) Escolha do Gestor de projeto;4) Construção do termo de abertura (Gestor de } \\
\text { Projeto); 5) Reunião de Kick-off (interna); 6) Captação de recursos humanos; 7) Reunião de } \\
\text { abertura com o ente público; 8) Criação da estrutura de um Comitê Gestor; 9) Monitoramento de } \\
\text { stakeholders; 10) Garantia de qualidade do produto (PMO); 11) Produção do relatório final (Gestor } \\
\text { do Projeto). }\end{array}$ \\
\hline $\begin{array}{l}\text { 足 } \\
0 \\
\text { y } \\
0\end{array}$ & $\begin{array}{l}\text { Gestor de Projetos, Gestor de Portfolio, Assistente de Projeto, Analista de Projeto, Líder de } \\
\text { Implantação, Patrocinador do Projeto (ente Público), Comitê Gestor (ente Público), Comitê Tático } \\
\text { (ente Público) e Comitê Operacional (ente Público). Áreas de inovação, novos negócios, contas e } \\
\text { comercial. }\end{array}$ \\
\hline 号 & $\begin{array}{l}\text { Infraestrutura: rede elétrica e lógica, equipamentos servidores de dados e aplicação, scanners, } \\
\text { computadores de mesa, certificados digitais e impressoras. }\end{array}$ \\
\hline$\widetilde{\mathscr{J}}$ & Sistemas de Informação: Repositório dos projetos na rede interna. \\
\hline
\end{tabular}




\begin{tabular}{|c|c|}
\hline 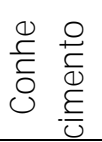 & $\begin{array}{l}\text { 1) Utiliza-se da estrutura por projetos. 2) Conhecimentos de gerenciamento de projetos. 3) } \\
\text { Conhecimentos de análise e desenvolvimento de sistemas. 4) Melhores Práticas PMBOK }\end{array}$ \\
\hline 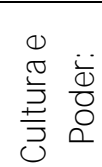 & $\begin{array}{l}\text { 1) Organização hierárquica. 2) A troca de membros da equipe gerencial pode ocasionar } \\
\text { problemas de comunicação e continuidade. 3) Há um relatório dos acontecimentos do } \\
\text { projeto, mas não existe uma cultura de consulta. }\end{array}$ \\
\hline
\end{tabular}

Fonte: Autores (2017).

O próximo passo é a confecção da planilha OM-3, ela dá sequência ao processo de descrição do modelo da organização, descrevendo detalhadamente todos os passos do processo, com a identificação das tarefas mais intensivas em conhecimento. Descreve-se quem realiza a tarefa, onde ela é realizada, qual o ativo proveniente desta tarefa, a caracteriza como uma atividade intensiva ou não, e por fim classifica-se com uma nota de 0 a 5 a relevância desta atividade.

Quadro 3 - OM-3 aplicada ao estudo.

\begin{tabular}{|c|c|c|c|c|c|c|}
\hline & \multicolumn{6}{|c|}{ Modelo da Organização - OM-3 Planilha de Detalhamento de Processos } \\
\hline № & Tarefa & Realizada por & Onde? & $\begin{array}{c}\text { Ativo de } \\
\text { Conhecimento }\end{array}$ & \begin{tabular}{|c|} 
Intensivo \\
$?$
\end{tabular} & $\begin{array}{c}\text { Relevâ } \\
\text { ncia }\end{array}$ \\
\hline 1 & $\begin{array}{l}\text { Prospectar os } \\
\text { clientes }\end{array}$ & $\begin{array}{c}\text { Analista de } \\
\text { Novos Negócios }\end{array}$ & $\begin{array}{c}\text { Áreas de Novos } \\
\text { negócios }\end{array}$ & Termo de projeto & Sim & 3 \\
\hline 2 & $\begin{array}{l}\text { Avaliar a prioridade } \\
\text { do projeto }\end{array}$ & $\begin{array}{l}\text { Gerente de } \\
\text { Portfólio }\end{array}$ & $\begin{array}{c}\text { Áreas de Novos } \\
\text { negócios }\end{array}$ & $\begin{array}{l}\text { Relatório de } \\
\text { prioridade do } \\
\text { projeto }\end{array}$ & Sim & 2 \\
\hline 3 & $\begin{array}{c}\text { Escolher o gestor do } \\
\text { projeto }\end{array}$ & $\begin{array}{l}\text { Gerente de } \\
\text { Portfólio }\end{array}$ & $\begin{array}{c}\text { Áreas de Novos } \\
\text { negócios }\end{array}$ & $\begin{array}{l}\text { Gestor do projeto } \\
\text { escolhido }\end{array}$ & Não & 0 \\
\hline 4 & $\begin{array}{c}\text { Construir o Termo de } \\
\text { abertura }\end{array}$ & $\begin{array}{l}\text { Gestor do } \\
\text { Projeto }\end{array}$ & $\begin{array}{l}\text { Unidade de } \\
\text { Justiça }\end{array}$ & $\begin{array}{l}\text { Termo de abertura } \\
\text { do Projeto }\end{array}$ & Sim & 1 \\
\hline 5 & $\begin{array}{l}\text { Realizar a reunião de } \\
\text { kidk-off (interna) }\end{array}$ & $\begin{array}{l}\text { Gestor do } \\
\text { Projeto }\end{array}$ & $\begin{array}{l}\text { Unidade de } \\
\text { Justiça }\end{array}$ & $\begin{array}{l}\text { Anúncio do início } \\
\text { do projeto por } \\
\text { toda organização }\end{array}$ & Não & 4 \\
\hline 6 & $\begin{array}{l}\text { Captar os recursos } \\
\text { humanos } \\
\text { necessários para o } \\
\text { projeto }\end{array}$ & $\begin{array}{l}\text { Gestor do } \\
\text { Projeto }\end{array}$ & $\begin{array}{l}\text { Unidade de } \\
\text { Justiça }\end{array}$ & $\begin{array}{l}\text { RH alocados ao } \\
\text { projeto }\end{array}$ & Sim & 4 \\
\hline 7 & $\begin{array}{l}\text { Efetuar reunião de } \\
\text { abertura com o ente } \\
\text { público }\end{array}$ & $\begin{array}{l}\text { Gestor do } \\
\text { Projeto }\end{array}$ & Ente Público & $\begin{array}{l}\text { Escopo do projeto } \\
\text { delineado }\end{array}$ & Sim & 2 \\
\hline 8 & $\begin{array}{l}\text { Criar a estrutura de } \\
\text { um Comitê Gestor }\end{array}$ & $\begin{array}{l}\text { Patrocinador do } \\
\text { Projeto }\end{array}$ & Ente Público & $\begin{array}{l}\text { Comitê Gestor } \\
\text { formalizado }\end{array}$ & Não & 0 \\
\hline 9 & $\begin{array}{l}\text { Listar e monitorar os } \\
\text { stakeholders }\end{array}$ & $\begin{array}{l}\text { Gestor do } \\
\text { Projeto }\end{array}$ & $\begin{array}{l}\text { Unidade de } \\
\text { Justiça }\end{array}$ & $\begin{array}{l}\text { Relatório mensal } \\
\text { do Projeto }\end{array}$ & Sim & 5 \\
\hline 10 & $\begin{array}{l}\text { Auferir a qualidade } \\
\text { do projeto }\end{array}$ & $\begin{array}{l}\text { Escritório de } \\
\text { PMO }\end{array}$ & $\begin{array}{l}\text { Unidade de } \\
\text { Justiça }\end{array}$ & $\begin{array}{l}\text { Relatório mensal } \\
\text { de qualidade do } \\
\text { Projeto }\end{array}$ & Sim & 3 \\
\hline 11 & Finalizar o projeto & $\begin{array}{l}\text { Gestor do } \\
\text { Projeto }\end{array}$ & $\begin{array}{l}\text { Unidade de } \\
\text { Justiça }\end{array}$ & $\begin{array}{l}\text { Relatório Final de } \\
\text { Projeto }\end{array}$ & Sim & 4 \\
\hline
\end{tabular}

Fonte: Autores (2017). 
A planilha do modelo de organização chama-se OM-4 e tem o intuito de analisar cada ativo de conhecimento anteriormente detalhado na planilha OM-3:

Quadro 4 - OM-4 aplicada ao estudo.

\begin{tabular}{|c|c|c|c|c|c|c|}
\hline \multicolumn{2}{|c|}{ Modelo da Organização } & \multicolumn{5}{|c|}{ OM-4 Planilha de Ativos de Conhecimento } \\
\hline $\begin{array}{c}\text { Ativo de } \\
\text { conhecimento }\end{array}$ & Possuído por & Usado em & $\begin{array}{l}\text { Forma } \\
\text { correta? }\end{array}$ & $\begin{array}{c}\text { Lugar } \\
\text { correto? }\end{array}$ & $\begin{array}{l}\text { No tempo } \\
\text { correto? }\end{array}$ & $\begin{array}{c}\mathrm{Na} \\
\text { quantidade } \\
\text { adequada? }\end{array}$ \\
\hline Termo de projeto & $\begin{array}{c}\text { Analista de } \\
\text { Novos Negócios }\end{array}$ & Prospectar os clientes & Sim & Sim & Sim & Sim \\
\hline $\begin{array}{l}\text { Relatório de } \\
\text { prioridade do } \\
\text { projeto }\end{array}$ & $\begin{array}{l}\text { Gerente de } \\
\text { Portfólio }\end{array}$ & $\begin{array}{c}\text { Avaliar a prioridade do } \\
\text { projeto }\end{array}$ & Sim & Sim & Sim & Sim \\
\hline $\begin{array}{l}\text { Termo de } \\
\text { abertura do } \\
\text { Projeto }\end{array}$ & $\begin{array}{l}\text { Gestor do } \\
\text { Projeto }\end{array}$ & $\begin{array}{c}\text { Construir o Termo de } \\
\text { abertura }\end{array}$ & Sim & Sim & Sim & Sim \\
\hline $\begin{array}{c}\text { Recursos } \\
\text { humanos } \\
\text { alocados ao } \\
\text { projeto }\end{array}$ & $\begin{array}{l}\text { Gestor do } \\
\text { Projeto }\end{array}$ & $\begin{array}{c}\text { Captar os recursos } \\
\text { humanos necessários } \\
\text { para o projeto }\end{array}$ & Não & Não & Não & Sim \\
\hline $\begin{array}{l}\text { Escopo do } \\
\text { projeto } \\
\text { delineado }\end{array}$ & $\begin{array}{l}\text { Gestor do } \\
\text { Projeto }\end{array}$ & $\begin{array}{l}\text { Efetuar reunião de } \\
\text { abertura com o ente } \\
\text { público }\end{array}$ & Sim & Sim & Sim & Sim \\
\hline $\begin{array}{l}\text { Relatório mensal } \\
\text { do Projeto }\end{array}$ & $\begin{array}{l}\text { Gestor do } \\
\text { Projeto }\end{array}$ & $\begin{array}{l}\text { Listar e monitorar os } \\
\text { stakeholders }\end{array}$ & Não & Não & Sim & Não \\
\hline $\begin{array}{l}\text { Relatório mensal } \\
\text { de qualidade do } \\
\text { Projeto }\end{array}$ & $\begin{array}{l}\text { Escritório de } \\
\text { PMO }\end{array}$ & $\begin{array}{l}\text { Auferir a qualidade do } \\
\text { projeto }\end{array}$ & Sim & Sim & Sim & Sim \\
\hline $\begin{array}{l}\text { Relatório Final de } \\
\text { Projeto }\end{array}$ & $\begin{array}{l}\text { Gestor do } \\
\text { Projeto }\end{array}$ & Finalizar o projeto & Não & Não & Sim & Sim \\
\hline
\end{tabular}

Fonte: Autores (2017).

O quadro 5 (OM-5) apresenta planilha para estudo de viabilidade do negócio, viabilidade técnica e do projeto, através de um checklist baseado nas planilhas anteriores.

Quadro 5 - OM-5 aplicada ao estudo.

\begin{tabular}{|c|c|}
\hline  & $\begin{array}{l}\text { Desenvolver um sistema para gerenciar o ambiente interno e externo ao projeto de e-gov. Na } \\
\text { perspectiva interna irá prospectar os recursos humanos mais aderentes a suprir as necessidades } \\
\text { do projeto de egovatravés de seus conhecimentos, habilidades e atitudes rastreadas em } \\
\text { documentos espontaneamente deixados pelo colaborador ao longo de sua experiência. Na } \\
\text { perspectiva externa, o monitoramento dos diversos stakeholders envolvidos nestes tipos de } \\
\text { projeto através de dados obtidos via web. O sistema propiciará melhores condições para o } \\
\text { trabalho cooperativo entre os colaboradores dos projetos de e-gov. O histórico das informações e } \\
\text { conhecimentos será preservado, de modo a permitir a reutilização por todos os envolvidos. }\end{array}$ \\
\hline 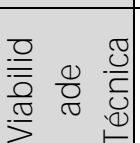 & $\begin{array}{l}\text { Empregar análise de dados com processos de KDD e KDT, além do uso de práticas aplicadas na } \\
\text { Web-Semântica, como interligação de conteúdos afins e que se complementam. Desta maneira, } \\
\text { pouco será alterado nos processos hoje existentes na organização. }\end{array}$ \\
\hline
\end{tabular}




\begin{tabular}{|c|c|}
\hline $\begin{array}{ll}\frac{0}{0} & \\
\frac{1}{0} & 0 \\
\frac{0}{0} & \frac{1}{0} \\
\frac{0}{0} & \frac{0}{0} \\
\frac{\overline{0}}{\overline{0}} & 0 \\
\frac{10}{10} & \end{array}$ & $\begin{array}{l}\text { Constatou-se a necessidade de Sistema Baseado em Conhecimento (SBC) que apoie nas tarefas } \\
\text { acima relacionadas, no mapeamento e monitoramento dos stakeholders internos e externos, pelo } \\
\text { fato de serem tarefas com uso intensivo de conhecimento e críticas à condução de um projeto de } \\
\text { e-gov. Neste contexto, verifica-se que tais projetos podem ter maior efetividade, pois terão } \\
\text { informações mais estruturadas, precisas e rápidas. }\end{array}$ \\
\hline 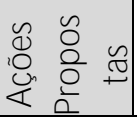 & $\begin{array}{l}\text { Possível desenvolvimento de Sistema Baseado em Conhecimento (SBC) para mapear e monitorar } \\
\text { o ambiente interno e externo a organização }\end{array}$ \\
\hline
\end{tabular}

$$
\text { Fonte: Autores (2017). }
$$

Finalizando o modelo de organização é possível verificar até o momento que é aplicável a proposição de um sistema baseado em conhecimento com o intuito de mapear e monitorar o ambiente da organização e seus stakeholders. A seguir, dar-se-á sequência na aplicação da meto dologia de Schreiber, et al (2002).

\subsection{Modelo da Tarefa}

A seguir são apresentadas as tabelas deste modelo, onde foram elencadas as principais tarefas, indicando se estas são intensivas em conhecimento ou não. Vale salientar que apenas as intensivas são trazidas para as tabelas posteriores.

Nota-se no Quadro 6 que para cada tarefa apresentada, são detalhados o posicionamento da tarefa na organização, o objetivo e valor agregado desta, onde ela se encaixa no fluxo do projeto, os objetos tratados, 0 tempo e controle, quais agentes responsáveis, conhecimento, competências e recursos envolvidos, além de itens de performance e qualidade esperados. Como forma de simplificar a apresentação desta tabela no quadro a seguir será apresentada somente uma tarefa, "Captar os recursos humanos necessários para o projeto", identificada como um dos gargalos da gestão de projeto na análise realizada.

Quadro 6 - TM-1 aplicada ao estudo.

\begin{tabular}{|c|c|}
\hline Modelo de Tarefa & TM-1 - Análise de Tarefas \\
\hline Tarefa & Captar os recursos humanos necessários para o projeto \\
\hline Organização & $\begin{array}{l}\text { 3a Tarefa do Gestor de Projeto - Essa tarefa é muito importante para garantir a } \\
\text { qualidade do projeto }\end{array}$ \\
\hline $\begin{array}{l}\text { Objetivo ou Valor } \\
\text { Agregado }\end{array}$ & $\begin{array}{l}\text { Objetivo: Auxiliar o gestor do projeto em conseguir os melhores recursos } \\
\text { humanos disponíveis ao projeto de forma mais célere. } \\
\text { Valor agregado: Diminuir sensivelmente o tempo gasto com a obtenção dos } \\
\text { recursos humanos para desenvolvimento dos projetos e aumentar qualidade } \\
\text { da escolha destes }\end{array}$ \\
\hline Dependências e Fluxo & $\begin{array}{l}\text { Entrada: Termo de abertura / Saída: Relação de colaboradores propícios a } \\
\text { participar do projeto }\end{array}$ \\
\hline Objetos manuseados & $\begin{array}{l}\text { Entrada: Termo de abertura / Saída: Relação de colaboradores propícios a } \\
\text { participar do projeto }\end{array}$ \\
\hline Tempo e controles & $\begin{array}{l}\text { Frequência: Quando necessário, mas ideal que seja feito apenas na abertura } \\
\text { do projeto; Duração: Demorado por não existir méto dos para agilizar este } \\
\text { processo. O gestor precisa ir aos setores em busca destes recursos. Controle: } \\
\text { Ao longo do projeto; Restrições: Recursos finitos e existem lacunas de } \\
\text { conhecimento }\end{array}$ \\
\hline Agentes & Gestor do Projeto \\
\hline $\begin{array}{l}\text { Conhecimento e } \\
\text { competência }\end{array}$ & $\begin{array}{l}\text { Estabelecer os conhecimentos necessários para cada posição no projeto, } \\
\text { assim como delinear as habilidades e atitudes que serão valorizadas pelo } \\
\text { Gestor do Projeto. }\end{array}$ \\
\hline Recursos & Acesso ao banco de informação dos recursos humanos \\
\hline Qualidade e Performance & O processo deve resultar numa escolha mais célere e precisa \\
\hline
\end{tabular}

Fonte: Autores (2017). 
0 quadro demonstra que, a atividade de captação de recursos humanos internos exige empenho e esforço cognitivo do agente (gestor do projeto), para recuperar informações sobre onde possam estar os possíveis recursos humanos para seu projeto. Ficou evidente que essa tarefa pode tornar-se um gargalo ao processo, caso ela não aconteça na velocidade adequada; o cenário ideal seria a ocorrência desta tarefa no início do projeto.

O Quadro 7 apresenta o preenchimento dos itens relativos a "Natureza do Conhecimento", "Forma do Conhecimento", e "Disponibilidade do Conhecimento". A mesma tarefa do quadro anterior foi utilizada.

Quadro 7 - TM-2 aplicada ao estudo.

\begin{tabular}{|c|c|c|}
\hline Modelo de Tarefa & \multicolumn{2}{|c|}{ TM-2 - Itens do Conhecimento } \\
\hline Nome & \multicolumn{2}{|c|}{ Captar os recursos humanos necessários para o projeto } \\
\hline Pertence à & \multicolumn{2}{|c|}{ Gestor do Projeto } \\
\hline Usado em & \multicolumn{2}{|c|}{ Durante todo o projeto } \\
\hline Domínio & \multicolumn{2}{|c|}{ Acesso ao banco de informação dos recursos humanos } \\
\hline Natureza do Conhecimento & & Gargalos/Melhorias \\
\hline Formal, rigoroso & & $\mathrm{X}$ \\
\hline Empírico, quantitativo & $\mathrm{X}$ & $\mathrm{X}$ \\
\hline Heurístico, Regras & $\bar{X}$ & $\bar{X}$ \\
\hline Altamente especializada & $x$ & $\mathrm{X}$ \\
\hline Baseado em experiência & $\mathrm{X}$ & $x$ \\
\hline Baseado em atividades & $\mathrm{X}$ & \\
\hline Incompleto & $X$ & $X$ \\
\hline Incerto, pode estar incorreto. & $\mathrm{X}$ & $\mathrm{X}$ \\
\hline Mudando rapidamente & $x$ & \\
\hline Difícil de verificar & $X$ & \\
\hline \multicolumn{3}{|l|}{ Tácito, difícil de transmitir } \\
\hline \multicolumn{3}{|l|}{ Forma do Conhecimento } \\
\hline Mente & $x$ & \\
\hline \multicolumn{3}{|l|}{ Papel } \\
\hline \multicolumn{3}{|l|}{ Formato Eletrônico } \\
\hline Habilidade da ação & $\mathrm{X}$ & $\mathrm{X}$ \\
\hline \multicolumn{3}{|l|}{ Disponibilidade do Conhecimento } \\
\hline Limitações de Tempo & & $X$ \\
\hline \multicolumn{3}{|l|}{ Limitações de espaço } \\
\hline Limitações de acesso & $\mathrm{X}$ & $\mathrm{X}$ \\
\hline Limitações de qualidade & $\mathrm{X}$ & $\mathrm{X}$ \\
\hline Limitações de forma & & \\
\hline
\end{tabular}

Fonte: Autores (2017).

Ao analisar o quadro 2 do modelo de tarefa é perceptível que a captação de recursos humanos internos é uma atividade tácita, baseada na experiência do gestor do projeto, tornando-se assim gargalo na condução do projeto, por parte da empresa de desenvolvimento de software.

\subsection{Modelo do Agente}

O próximo passo da metodologia CommonKADS é a aplicação modelo do agente, que fornece um arcabouço para avaliação dos agentes envolvidos. Visando simplificar o estudo, é apresentado a seguir: 0 agente "Gestor do Projeto", o principal agente do ambiente pesquisado. Em uma seleção de 11 tarefas dentro deste ciclo analisado, sendo 8 ativas em conhecimento, 5 são desempenhadas por este agente. 
Quadro 8 - AM-1 aplicada ao estudo.

\begin{tabular}{|c|c|}
\hline Modelo de Agente & AM-1 -Planilha de Agentes \\
\hline Nome & Gestor do Projeto \\
\hline Organização & Faz parte de diretoria de operações \\
\hline Envolvido em & $\begin{array}{l}\text { 1) Construir o Termo de abertura; 2) Captar recursos humanos para o projeto; 3) Efetuar a } \\
\text { reunião de abertura com o ente público; 4) Listar e monitorar os stakeholders; 5) Finalizar } \\
\text { o projeto. }\end{array}$ \\
\hline Comunicação com & $\begin{array}{l}\text { Analista de novos negócios, Gestor de Portfolio, Assistente de Projeto, Analista de Projeto, } \\
\text { Líder de Implantação, Patrocinador do Projeto (org. Público), Comitê Gestor (org. Público), } \\
\text { Comitê Tático (org. Público) e Comitê Operacional (org Público). Áreas de inovação, novos } \\
\text { negócios, contas e comercial. }\end{array}$ \\
\hline Conhecimento & $\begin{array}{l}\text { Conhecimento completo das atividades, do ramo e da área de atuação da empresa. } \\
\text { Conhecimento do documento de projeto elaborado. } \\
\text { Conhecimento em gerência de projetos. }\end{array}$ \\
\hline Outras competências & $\begin{array}{l}\text { Mapeamento dos conhecimentos e habilidades existentes na organização e identificar a } \\
\text { existência de lacunas no conhecimento necessário para a execução do projeto }\end{array}$ \\
\hline $\begin{array}{l}\text { Reponsabilidades e } \\
\text { restrições }\end{array}$ & $\begin{array}{l}\text { Presidir reuniões para elaboração de termo de abertura, prezar por prazos e qualidade das } \\
\text { entregas, selecionar e engajar a equipe envolvida, finalizar o projeto, criar relatórios do } \\
\text { processo e lições aprendidas, e liberar os recursos para serem utilizados e novos projetos }\end{array}$ \\
\hline
\end{tabular}

Fonte: Autores (2017).

Percebe-se a partir do quadro 7 a importância do gestor de projeto no processo de gerenciamento em análise, e seu envolvimento com quase todas as onze tarefas listadas como fundamentais desse processo. Também estabelece comunicação com todos os participantes do processo e tem muitas das responsabilidades vinculadas a si.

\subsection{Modelo da organização, tarefa e agente}

O Modelo de Organização, Tarefa e Agente, Planilha OTA-1 (Quadro 9) agrega as planilhas TM-1, TM-2 e AM-1 por meio de comparativo entre a situação anterior e a pretendida. Nesta etapa, a integração do Sistema Baseado em Conhecimento (SBC) com a organização é avaliada.

Quadro 9 - OAT-1 aplicada ao estudo.

\begin{tabular}{|l|l|}
\hline $\begin{array}{l}\text { Modelo de } \begin{array}{l}\text { Organização, } \\
\text { Tarefa e Agentes }\end{array} \\
\text { OTA-1 -Planilha com Checklist de Impacto e Melhoramentos }\end{array}$ \\
\hline $\begin{array}{l}\text { Impactos e } \\
\text { mudanças na } \\
\text { organização }\end{array}$ & $\begin{array}{l}\text { O desenvolvimento deste sistema traria maior agilidade e qualidade no processo de } \\
\text { seleção dos recursos humanos que irão participar do projeto, consequentemente irá se } \\
\text { obter mais efetividade nas soluções de egov. Ficará evidente com este sistema as } \\
\text { lacunas de conhecimento que poderão servir de mapa para futuras capacitações }\end{array}$ \\
\hline $\begin{array}{l}\text { Impactos e } \\
\text { mudanças } \\
\text { espećficos a } \\
\text { tarefas / agentes }\end{array}$ & $\begin{array}{l}\text { Trará impacto aos colaboradores, ao manter as memórias do projeto atualizadas. O } \\
\text { trabalho do gestor de projetos será facilitado, pois terá um mapa em suas mãos das } \\
\text { competências existentes na organização. }\end{array}$ \\
\hline $\begin{array}{l}\text { Atitudes e } \\
\text { Compromissos }\end{array}$ & $\begin{array}{l}\text { Para que o sistema seja efetivo é necessário que os colaboradores envolvidos com } \\
\text { projetos de e-gov prezem por registrar a memória de suas ações nos devidos } \\
\text { repositórios. Etambém, disponibilizar recursos computacionais para que as lideranças } \\
\text { da organização sejam mais colaborativas, em relação a liberação de recursos } \\
\text { apontados pelo sistema, possibilitando maior efetividade aos projetos nesta área. }\end{array}$ \\
\hline Ações Propostas & $\begin{array}{l}\text { Sistema baseado em conhecimento que monitore os stakeholders. Esse projeto } \\
\text { utilizará análise de dados com processos de KDD e KDT, além do uso de práticas } \\
\text { aplicadas na Web-Semântica, como interligação de conteúdos afins e que se } \\
\text { complementam. }\end{array}$ \\
\hline
\end{tabular}

Fonte: Autores (2017). 
Com a aplicação da metodologia CommonKADS ao de gerenciamento de projeto de egov, verificou-se oportunidades de melhorias por meio de um Sistema Baseado em Conhecimento (SBC), para apoiar atividades intensivas em conhecimento. A tarefa de maior relevância que se sugere apoiar com o sistema é a seleção dos recursos humanos internos pelo gestor, para compor de forma mais adequada a equipe do projeto, em conformidade com os requisitos e características do projeto a ser executado, e apresentar uma visão ampla das lacunas de conhecimento existente na organização.

Por sua vez, tarefas como a escolha do gestor do projeto, que não foi considerada de maior relevância na construção deste trabalho, também poderá usufruir do sistema que irá monitorar o conhecimento da organização.

\section{CONSIDERAÇÕES FINAIS}

Este estudo teve como principal objetivo a aplicação do CommonKADS (Schreiber et al, 2002), para identificar soluções para as especificidades enfrentadas pelo gestor de projetos de e-gov, no contexto de uma empresa desenvolvedora de software

Como principal resultado na aplicação da metodologia, os entrevistados informaram que uma das principais dificuldades é obtenção de recursos humanos para seus projetos. Isso porque não há, hoje, a automatização e sistematização deste processo. 0 gerente de projeto percorre as unidades de negócio em busca dos especialistas, o que pode acarretar em tempo perdido e desperdício de conhecimento.

A implantação de um sistema de apoio poderá auxiliar a empresa desenvolvedora de software na identificação de profissionais disponíveis, e com conhecimentos compatíveis com a necessidade do gestor, e também, detectar as lacunas de conhecimentos na organização, com a finalidade de supri-las com capacitações específicas.

Outra lacuna que se pôde observar foi a inobservância parcial dos processos de trabalhos por parte dos gerentes de projeto, pois há uma grande quantidade de projetos sendo executados de forma concorrente, e um número insuficiente de gerentes. Tal situação que pode prejudicar a elaboração de artefatos e documentos, a exemplo do registro das "lições aprendidas" de um determinado projeto, seja por falta de tempo ou baixa priorização da atividade, ou ainda pela ausência de um sistema mais adequado a gestão dos projetos, que disponibilize recursos para o compartilhamento efetivo do conhecimento. Percebeu-se que consultas aos repositórios de projetos da empresa não são frequentes por parte dos gerentes de projeto, pois o método de busca não é intuitivo ou interessante, e muitas vezes, o repositório não é atualizado.

Ainda relacionado ao repositório de projetos, outro ponto de impacto é a rotatividade de colaboradores. Um grupo já engajado com o projeto é substituído por um novo grupo, podendo ser reticente ou desinteressado, prejudicando 0 andamento e sucesso do projeto. Essa situação reafirma a importância da estruturação e consulta de um repositório de artefatos e dados do projeto para atualização do novo grupo sobre o andamento do projeto.

Este resultado da pesquisa corrobora com a fala de Sarantis et al (2010) de que o novo desafio para administração pública de projetos de egové baseado na exploração dos seus recursos de conhecimento a fim de melhorar seus projetos.

Como sugestão de pesquisas futuras propõe-se desenvolver estudos longitudinais sobre como essas soluções possam ser implantadas (demonstrando a parte técnica com ontologias e taxonomia do futuro SBC) e testar, assim, sua efetividade. 


\section{REFERÊNCIAS}

ABEL, Mara; FIORINI, Sandro Rama. Uma revisão da Engenharia do Conhecimento: Evolução, Paradigmas e Aplicações. International J ournal of Knowledge Engineering and Management (IJ KEM), v. 2, n. 2, p. 1-35, 2013.

AICHHOLZER, Georg. Scenarios of e-Government in 2010 and implications for strategy design. Electronic journal of e-government, v. 2, n. 1, p. 1-10, 2004.

BIGDELI, Alinaghi Ziaee; KAMAL, Muhammad Mustafa; DE CESARE, Sergio. Electronic information sharing in local government authorities: Factors influencing the decision-making process. International J ournal of Information Management, v. 33, n. 5, p. 816-830, 2013.

CHANG, Mong-Yuan et al. The research on the critical success factors of knowledge management and classification framework project in the Executive Yuan of Taiwan Government. Expert Systems with Applications, v. 36, n. 3, p. 5376-5386, 2009.

DIAS, Maria Madalena; PACHECO, Roberto Carlos dos Santos. Uma visão geral de metodologias para desenvolvimento de sistemas baseados em conhecimento. Revista de Ciência da Informação, v. 10, n. 5, artigo $3,2009$.

FRANKE, Roland et al Influential factors for e-government success in the Middle East: Case study evidence from Saudi Arabia. International Journal of Electronic Government Research (IJ EGR), v. 11, n. 1, p. 39-62, 2015.

GIL, Antonio Carlos. Métodos e técnicas de pesquisa social. 6. ed. São Paulo: Atlas, 2008.

GUHA, Joydeep; CHAKRABARTI, Bhaskar. Making e-government work: Adopting the network approach. Government Information Quarterly, v. 31, n. 2, p. 327-336, 2014.

KUMAR, Rajendra; BEST, Michael L. Impact and sustainability of e-government services in developing countries: Lessons learned from Tamil Nadu, India. The Information Society, v. 22, n. 1, p. 1-12, 2006.

LOPES, Luiz Fernando et al. Sistema de conhecimento para diagnóstico em acupuntura: uma modelagem usando o CommonKADS. Gestão \& Produção, v. 18, n. 2, p. 351-366, 2011.

MERRIAM, Sharan B. Qualitative Research and Case Study Applications in Education: revised and expanded from case study research in Education. San Francisco: J ossey-Bass Publishers, 1998.

PACHECO, Ro berto Carlos dos Santos et al. Do e-Gov a e-Governança: modelo de e-gov voltado à governaça pública. In: HYASHI, Maria Cristina P. I.; RIGOLIN, Camila C. D.; BARBOSA, Henrianne. (Org.). Governo na Web: Reflexões Teóricas e Práticas. Campinas: Alínea, 2015. v. 2. p. 53-90.

PANDA, Prabir; SAHU, Ganesh P. Electronic government procurement implementation in India: a cross sectional study. International J ournal of Business Information Systems, v. 18, n. 1, p. 1-25, 2014.

PARK, Tae-Young; KIM, J un-Youn. The capabilities required for being successful in complex product systems: case study of Korean e-government. Asian Journal of Technology Innovation, v. 22, n. 2, p. 268-285, 2014.

PURÓN-CID, Gabriel. The Dimensions of Knowledge in E-government Adoption. Gestión y Política Pública, v. 22, p. 213-259, 2013. 
RANA, Nripendra P.; DWIVEDI, Yogesh K.; WILLIAMS, Michael D. Analysing challenges, barriers and CSF of egov adoption. Transforming Government: People, Process and Policy, v. 7, n. 2, p. 177-198, 2013.

SARANTIS, Demetrios et al. A critical assessment of project management methods with respect to electronic government implementation challenges. Systemic Practice and Action Research, v. 23, n. 4, p. 301-321, 2010.

SCHREIBER, Guus et al. Knowledge engnineering and management: the CommonKADS methodology. Cambridge/Massachussets: MIT Press, 2002.932 p.

SEWALD JUNIOR, Egon et al. Modelagem de Sistema baseado em Conhecimento em um Tribunal de Justiça utilizando CommonKADS. Revista Democracia Digital e Governo Eletrônico, v. 2, n. 7, p. 160-189, 2012.

SUREEPHONG, Pradorn et al. Knowledge engineering technique for cluster develo pment. In: INTERNATIONAL CONFERENCE ON KNOWLEDGE SCIENCE, ENGINEERING AND MANAGEMENT, 2., 2007, Berlin. Proceedings... Berlin: Springer Berlin Heidelberg, 2007. p. 661-666.

TAYLOR, Steven J.; BOGDAN, Ro bert. Introduction to qualitative research methods: The search for meaning. Hoboken, New Jersey: John Wiley \& Sons, 1984.

YIN, Robert K. Estudo de Caso: Planejamento e Métodos. Porto Alegre: Bookman, 2015.

VAN DER VELDEN, Christian; BIL, Cees; XU, Xinghuo. Adaptable methodology for automation application development. Advanced Engineering Informatics, v. 26, n. 2, p. 231-250, 2012.

WERNECK, V. M. et al. Uma Avaliação da Metodologia MAS-CommonKADS. [2006]. Disponível em: $<$ https://projetos.inf.ufsc.br/arquivos_projetos/projeto_822/Artigo3.pdf >. Acesso em: 24 nov. 2017. 